\title{
BRONCES EPIGRÁFICOS INÉDITOS DEL MUSEO DE BURGOS ${ }^{1}$
}

\section{NEW BRONZE INSCRIPTIONS IN THE MUSEUM OF BURGOS}

\author{
Javier del Hoyo y Mariano Rodríguez Ceballos \\ $U A M-U A H$ \\ javier.delhoyo@uam.es \\ ORCID: 0000-0003-4669-5875 \\ mrodriguezceballos@gmail.com \\ ORCID: 0000-0003-4629-0712
}

DOI: $10.1387 /$ veleia.16985

\begin{abstract}
Resumen: Se publican cinco fragmentos de bronce, cuatro de ellos con inscripción, procedentes de Solarana y Clunia, conservados en el Museo de Burgos.

Palabras clave: epigrafía jurídica, bronce, Solarana, Clunia.

Abstract: In this paper the authors published five fragments of bronze, four with latin inscription, from Solarana and Clunia, preserved in the Museum of Burgos.

Keywords: Roman Epigraphy, bronze, Solarana, Clunia.
\end{abstract}

Recibido: 16-03-2016

Definitivo: 18-03-2016

La exposición sobre Los bronces romanos en España, que tuvo lugar en Madrid en 1990, vino a demostrar la importancia que la Península Ibérica había tenido en época romana en lo que denominamos epigrafía jurídica. En ella se expusieron casi todas las piezas que habían sido halladas hasta ese momento. Tuvieron especial relieve los recientes descubrimientos de la década de los ochenta, como la Tabula Siarensis, las seis tablas de la Lex Irnitana, o los numerosos documentos encontrados de forma fragmentaria ${ }^{2}$.

La década de los noventa no fue menos generosa. El senadoconsulto de Gneo Pisón padre con todas sus copias (Caballos, Eck y Fernández 1996), el nuevo bronce de Osuna (Caballos 2006), o el edicto de Bembibre ${ }^{3}$ (León), pusieron a Hispania en la cúspide de la epigrafía jurídica. Por ello mismo, aquella obra de Álvaro D’Ors (1953), que en su día constituyó un estudio fundamental en la materia tanto por las piezas aportadas, como sobre todo por los comentarios, ha quedado ya incompleta y obsoleta. No es de extrańar, por ello, que algunos estudiosos hayan vuelto varias veces

1 Nuestro más sincero agradecimiento a Marta Negro, directora del Museo de Burgos, que nos ha permitido estudiarlas y fotografiarlas en marzo de 2016, con vistas a su publicación.
2 Un intento de puesta al día, aunque incompleto y ceñido a una sola provincia, puede verse en González 2008.

3 Remitimos a Sánchez-Palencia y Mangas 2000. Más completo puede verse el conjunto de estudios hechos sobre la tabla en la monografía coordinada por Grau y Hoyas 2001. 
sobre el tema, aunque sólo sea para hacer un recuento o inventario de epígrafes en bronce. Así, por ejemplo, F. Beltrán en los Congresos Internacionales de Epigrafía Griega y Latina (Roma $1997^{4}$ o Berlín 2012).

Pero si las grandes piezas, esas tablas de bronce con su marco exterior, sus orificios para ser colgadas y su largo texto distribuido en varias columnas, son fundamentales para el conocimiento del Derecho romano, la municipalización, la organización de la vida urbana, etc., los pequeños fragmentos también pueden proporcionarnos noticias que, aun pareciendo insignificantes, nos sitúan tras la pista de acuerdos entre pueblos, o bien partes de diplomas, senadoconsultos, etc. ${ }^{5}$

Y así, entre las muchas sorpresas que puede regalarnos el Museo de Burgos, encontramos en los almacenes un bronce procedente de Clunia, y en la sala de arqueología de la segunda planta (vitrina 1) hemos visto expuestos otros cuatro bronces inéditos hallados en Solarana (Burgos), tres de ellos con inscripción (todos bajo el mismo n. ${ }^{\circ}$ de inventario, 8564).

Pertenecen estos a diversas placas, como puede verse por el diferente grosor de las piezas. La paleografía, por su parte, es muy distinta. Fueron entregados por el señor Yáñez, vecino de Quintanilla del Agua (Burgos), para que formaran parte de los fondos del Museo ${ }^{6}$. Parece que se encontraron de forma casual ${ }^{7}$, en pleno campo, en el transcurso de unas labores agrícolas, junto a otros bronces. Entre estos había un puente de fíbula de charnela, decorado con nervio central resaltado y punteado $(4,7 \times 0,7 \times 0,2 \mathrm{~cm})$; el pie de la fíbula se remata con un botón esférico. Dentro de este conjunto se encontraba también una cabeza de jabalí de bronce realizada a molde con detalles anatómicos y el pelaje inciso $(5,2 \times 2,2 \times 2,3 \mathrm{~cm})$; unas pinzas de cirujano completas también de bronce y rematadas con una cabecera circular sobre base trapezoidal invertida, que se decora con dos molduras transversales en los bordes laterales $(14,7 \times 0,8 \times 0,6 \mathrm{~cm})$; y un bucráneo de bronce con los detalles anatómicos realizados mediante incisión e impresión $(3,5 \times 3,6 \times 0,8 \mathrm{~cm})$. Todas estas piezas permanecen inéditas esperando que algún especialista las estudie y publique.

Las inscripciones que aquí presentamos hay que añadirlas a las que ya se habían encontrado en Solarana, es decir, dos árulas votivas (del Hoyo y Cogollos 2005-2006, 231-236), y quizás una tercera depositada en el Museo de Burgos, que los primeros editores dieron como procedente de Lerma (Abásolo y Albertos 1978, 417-418, n. ${ }^{\circ}$ 2), pero que al parecer fue encontrada en la vega del Arlanza. Presenta rasgos formales similares a las dos árulas citadas: material (caliza muy porosa), pequeño tamaño, paleografía, decoración de la cabecera, etc.

\footnotetext{
4 En este trabajo hace una presentación en forma de listado de 95 piezas.

5 Caballos y Fernández comentan con acierto la necesidad de estudiar todos los fragmentos por pequeńos que sean: "Con lo dicho se comprende que siga resultando tarea absolutamente prioritaria la de la recuperación y exhaustiva edición de todos los bronces jurídicos a nuestro alcance. Hasta ahora se han editado los grandes textos, mientras que, con relación a los pequeños fragmentos, aún se mantiene el prurito de publicar sólo
}

aquellos cuyo contenido hemos llegado a identificar" $(1999,657)$.

${ }^{6}$ Ingresaron en el Museo de Burgos en julio de 1987, donados por José David Sacristán, en su calidad de arqueólogo de urgencia de la Consejería de Educación y Cultura de la Junta de Castilla y León, junto con otras muchas piezas de la zona (ficha de entrada en el Museo).

7 El hecho de que se hayan encontrado todos los bronces juntos, hace sospechar la labor previa de algún furtivo con detector de metales. 
1. Fragmento trapezoidal de placa de bronce procedente de Solarana. Conserva parte del borde superior, que se encuentra alisado, y presenta a la izquierda un orificio para ser fijada en la pared, por lo que posiblemente se trate del ángulo superior izquierdo. Conserva restos de letras en dos líneas con distintas alturas (fig. 1).

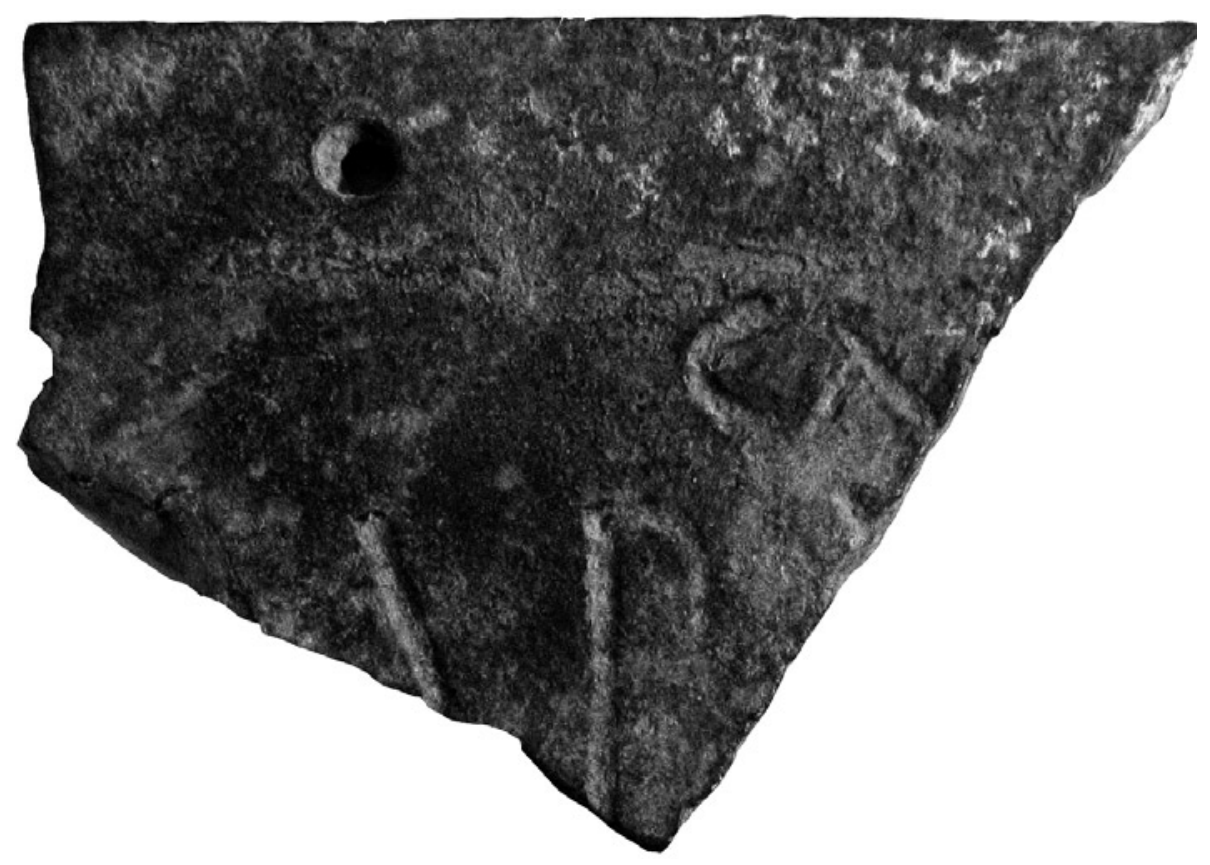

Soporte: $(4,3) \times(6,1) \times 0,4 \mathrm{~cm}$.

Altura letras: 0,$6 ;(1,7) \mathrm{cm}$.

Interlineado: $0,3 \mathrm{~cm}$.

$$
\begin{aligned}
& C n[---] \\
& +p+[--]
\end{aligned}
$$

Resulta imposible tanto reconstruir como traducir el texto a partir de los mínimos restos conservados. En l. 1 podríamos tener el praenomen Gn(aeus). En 1.2 cabe la posibilidad de interpre$\operatorname{tar} A / M$ para la primera +, seguida de una $P$, y el vértice superior izquierdo de una $A$, o $V$ (menos probable una $X$ por el contexto). 
2. Fragmento de placa de bronce, rota por los cuatro lados, que conserva dos renglones de texto. Se observan signos de interpunción. La incisión es fina. $T$ con brazo ondulante (fig. 2).

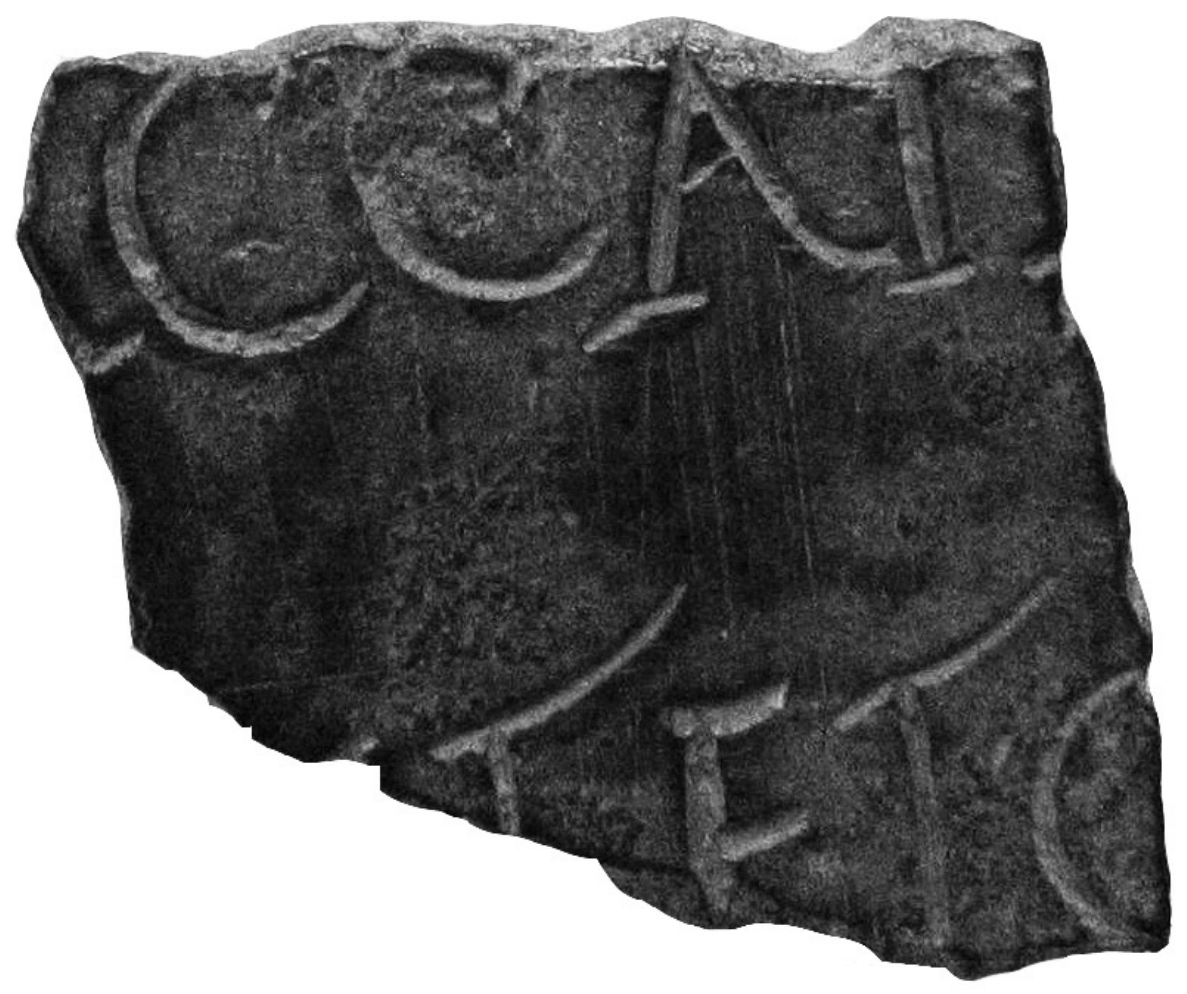

Soporte: $(2,3) \times(2,3) \times 0,2 \mathrm{~cm}$.

Altura letras: 0,$6 ;(0,6) \mathrm{cm}$.

Interlineado: $1 \mathrm{~cm}$.

$$
\begin{aligned}
& {[---] \text { accat }+[---]} \\
& {[---]+t e t \cdot+[--]}
\end{aligned}
$$

Cronología: Por los rasgos paleográficos parece de época flavia o finales del siglo I. 
3. Fragmento trapezoidal de placa de bronce, correspondiente al ángulo inferior derecho, cuyos bordes conserva. Mantiene las dos últimas letras de la que estimamos como última línea. El lecho es grueso. Parece contener una línea de guía debajo de la inscripción (fig. 3).

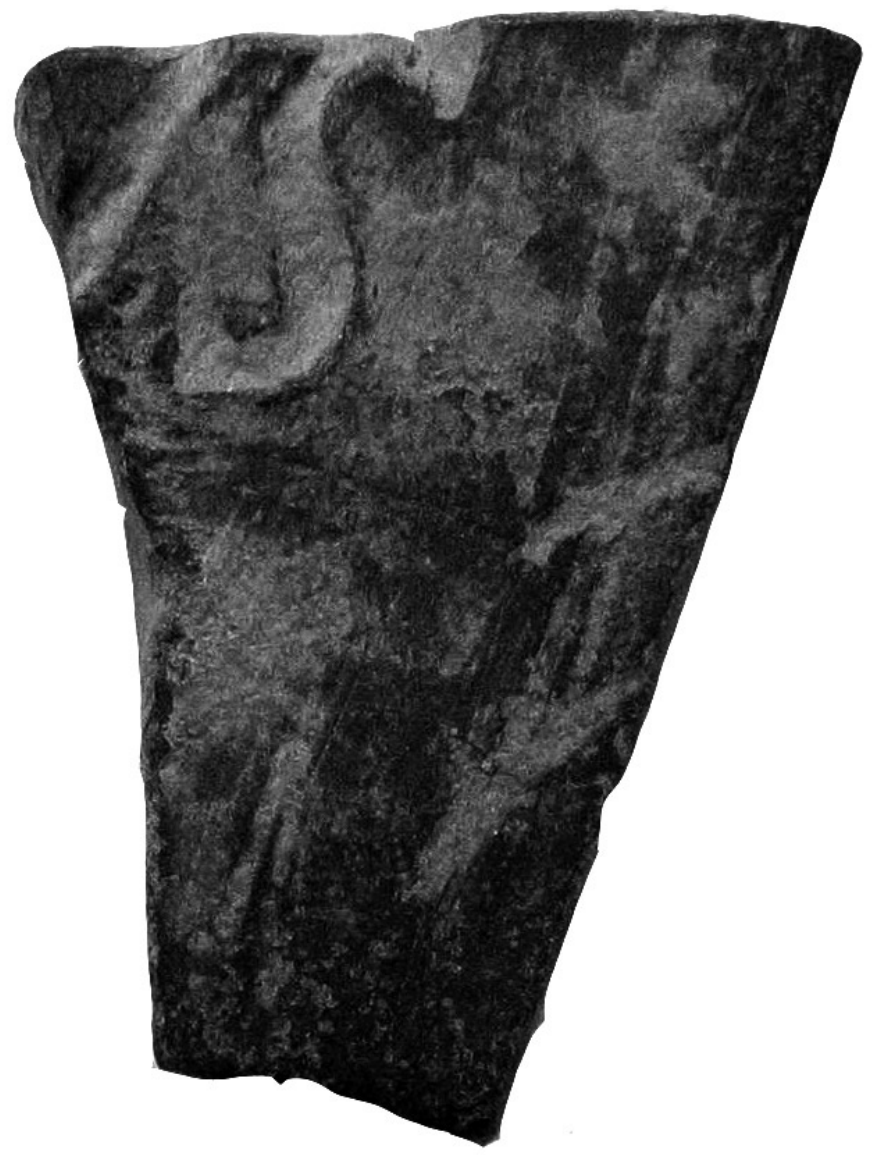

Soporte: $(2,9) \times(2) \times 0,25 \mathrm{~cm}$.

Altura letras: $0,9 \mathrm{~cm}$.

$$
[---] \text { us }
$$


4. Fragmento triangular de moldura correspondiente a una tabla de bronce, que pudo servir de asa de una tabula ansata o de acrótera. Mide $(3,3) \times(4,5) \times 0,6 \mathrm{~cm}$ (foto 4). Presenta dos surcos paralelos bien marcados en los laterales de la cara epígrafa, y en los bordes dos protuberancias, de las que se pudo sostener la propia tabla, similares a la tabula ansata del Museo de las Termas de Diocleciano (CIL VI 844) o a la tésera de Mulva (AA. VV. 1990 176, n. ${ }^{\circ}$ 26).

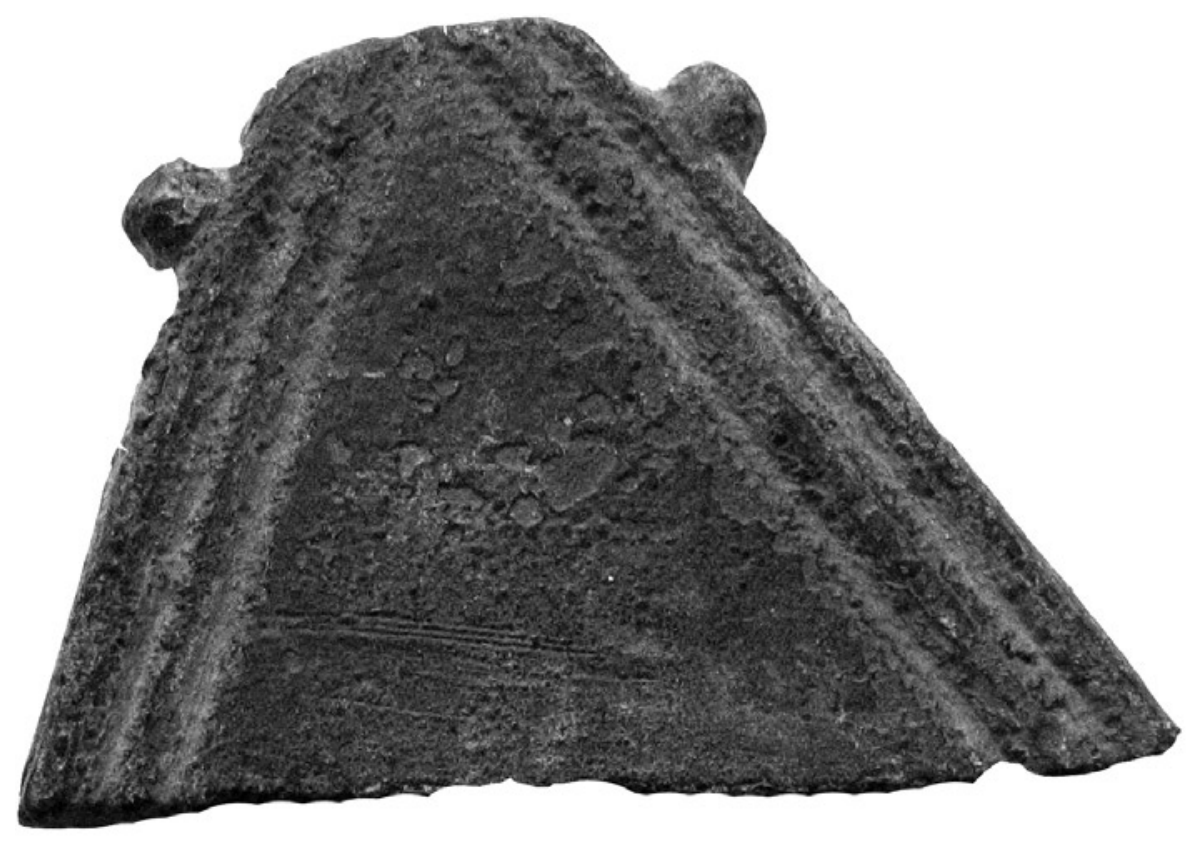


5. Fragmento trapezoidal de placa de bronce, hallado de forma casual en la zona del decumanus de Clunia en agosto de 1991. Fue entregado por el arqueólogo Juan Cristóbal Villanueva al Museo de Burgos, en cuyos almacenes se conserva sin número de inventario. El estado de conservación es bueno; tiene una burbuja en el primer interlineado, fruto de una mala fundición. Presenta letras en tres líneas. Por el grosor, pudo pertenecer a una tabla de notables dimensiones (fig. 5).

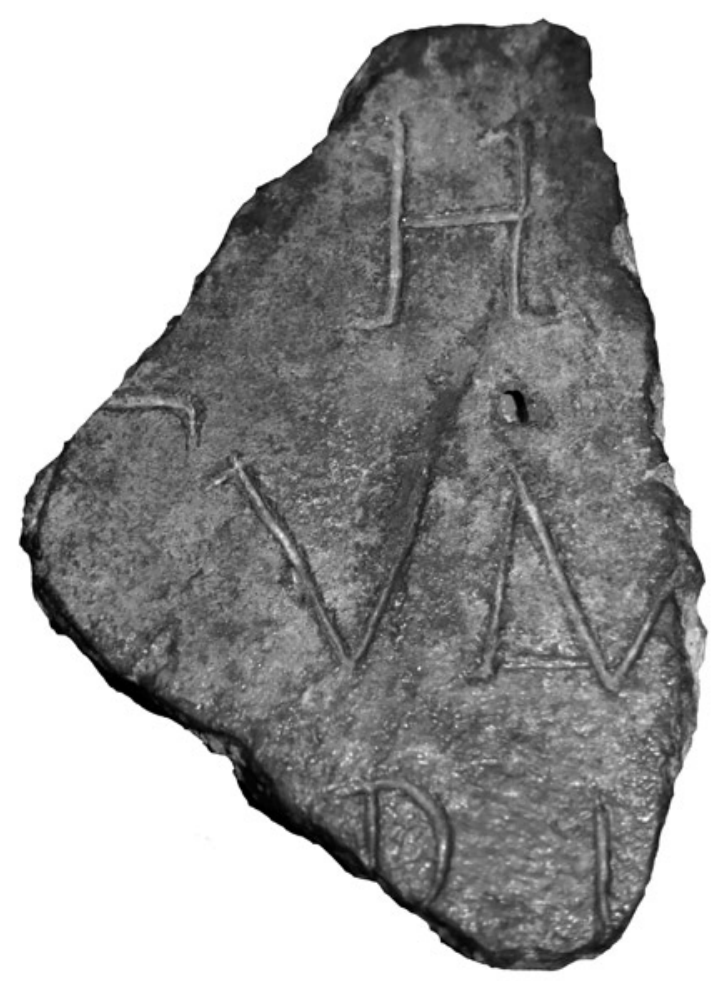

Soporte: $(5,8) \times(3,7) \times 0,6 \mathrm{~cm}$.

Altura letras: 1,$2 ; 1,1-1,6 ;(0,6) \mathrm{cm}$

Espacios interlineales: $0,8 \mathrm{~cm}$.

$$
\begin{aligned}
& \text {----- } \text { b[---] } \\
& {[---] \text { cum }[---]} \\
& {[---] b+[--]}
\end{aligned}
$$


No es el único fragmento de epigrafía jurídica hallado en Clunia, donde ya en 1968 se encontraron tres fragmentos correspondientes a dos tesserae (De Palol y Vilella 1987: n. ${ }^{\circ} 113$ y 115), y otro más en 1972 (De Palol y Vilella 1987: n. ${ }^{\circ} 114$ ), además de la célebre tabula de bronce hallada completa en 1887 y conservada en el MAN de Madrid (De Palol y Vilella 1987: n. ${ }^{\circ}$ 116). De hecho, la secuencia que nos ha llegado podría corresponder a la parte central de una tabula de hospitium, con un texto similar a ésta (véase fig. 6), y podría constituir una copia más de las varias que pudieron hacerse. El espacio sin grabar anterior a la $\mathrm{H}$ parece indicar que estamos ante una inicial y le convendría a una palabra como hospitium. El grosor parece apuntar a una tabula de gran tamaño.

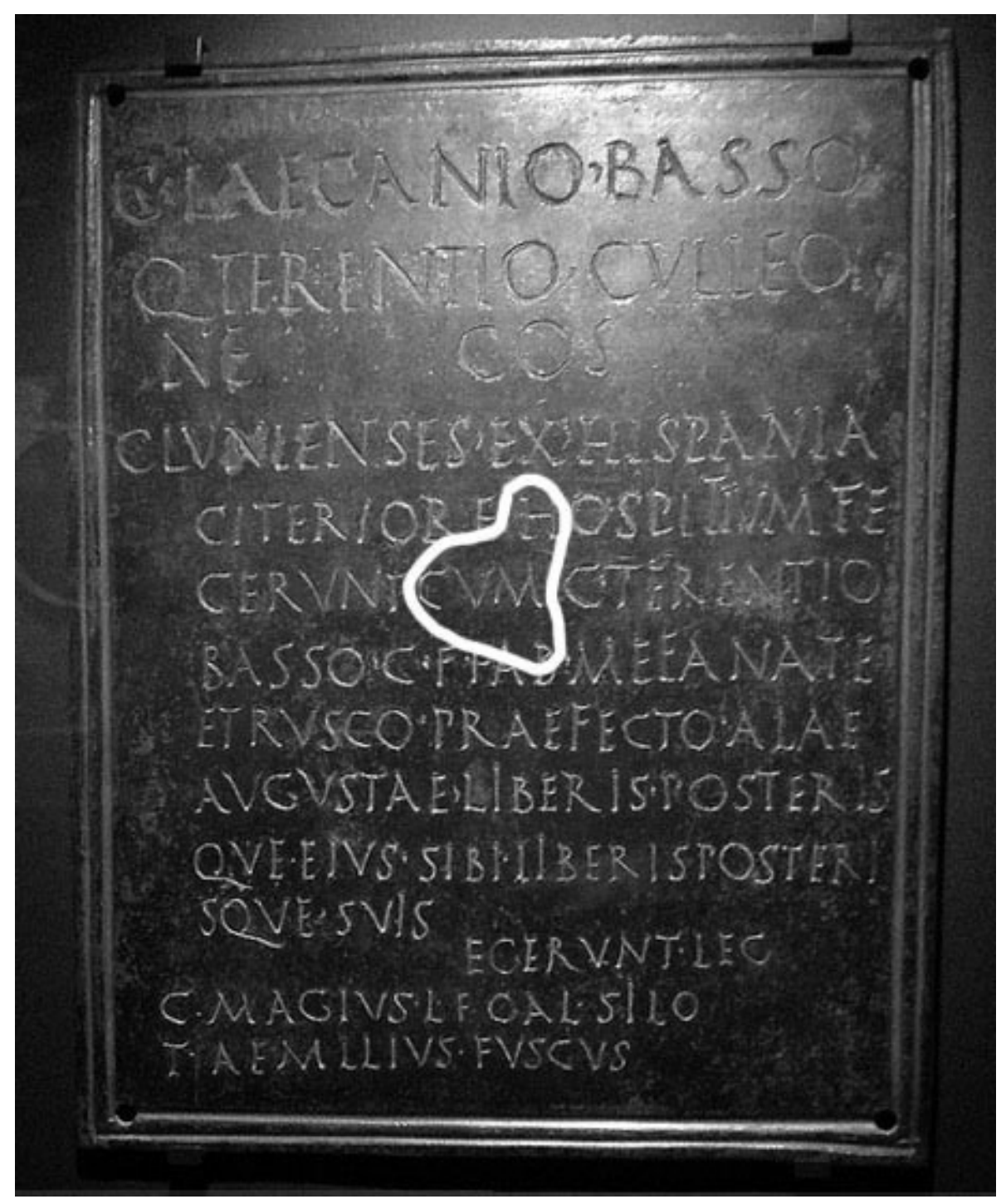

A las piezas anteriormente dichas hay que añadir el fragmento de bronce al que hace referencia Hübner (1894: 178) enviado por Fita, que estaba en la colección de F. Álvarez Guijarro, cuyo paradero es hoy desconocido y que no ha sido publicado desde entonces en ninguna obra. 


\section{BibliografíA}

AA. VV., 1990, Los bronces romanos en España, Madrid.

AвÁsolo, J. A., Albertos, L., 1978, «Nuevos hallazgos de inscripciones romanas en la provincia de Burgos», BSEAA XLIV, 416-418.

Beltrán, F., 1999, «Inscripciones sobre bronce: ¿un rasgo característico de la cultura epigráfica de las ciudades hispanas?» en: XI Congresso Internazionale di Epigrafia Greca e Latina, Roma 18-24 settembre 1997, vol. II, Roma, 21-37.

—, 2014, "Honos clientium instituit sic colere patronos. Un tipo epigráfico público y 'privado': las tábulas de hospitalidad y patronato» en: Akten XIV Congressus Internationalis Epigraphiae Graecae et Latinae 27.31. Augusti MMXII, Berlin, 492-494.

Caballos, A., 2006, El nuevo bronce de Osuna y la politica colonizadora romana, Sevilla.

Caballos, A., Eck, W., Fernández, F., 1996, El senadoconsulto de Gneo Pisón padre, Sevilla.

Caballos, A., Fernández, F., 1999, "Novedades, estado de la cuestión y expectativas de la epigrafía en bronce en Andalucía», en: XI Congresso Internazionale di Epigrafia Greca e Latina, Roma 18-24 settembre 1997, vol. I, Roma, 653-660.

$C I L=$ Hübner, A., 1869, Corpus Inscriptionum Latinarum, vol. II, Berlin.

GonzÁlez, J., 2008, Epigrafía jurídica de la Bética, Roma.

Grau, L., Hoyas, J. L. (eds.), 2001, El bronce de Bembibre. Un edicto del emperador Augusto, León.

Del Hoyo, J., Cogollos, A., 2005-2006, "Aras romanas inéditas procedentes de Solarana (Burgos)», Boletín de la Asociación Española de Amigos de la Arqueologia, 44, 231-236.

HüBNER, E., 1894, «Bronces epigráficos de Clunia y de Bílbilis», BRAHXXIV, 177-179.

D’Ors, Á., 1953, Epigrafía jurídica de la España romana, Madrid.

De Palol, P., Vilella, J., 1987, Clunia II. La epigrafía de Clunia, Madrid.

Sánchez-Palencia, F. J., Mangas, J. (coords.), 2000, El Edicto del Bierzo. Augusto y el Noroeste de Hispania, Ponferrada. 